University of Wollongong

Research Online

Faculty of Business - Papers (Archive)

Faculty of Business and Law

2013

Assessment guiding learning: developing graduate qualities in an experiential learning programme

Michael David Clements

Swinburne University of Technology, clements@uow.edu.au

Bonnie Amelia Dean

University of Wollongong, bcord@uow.edu.au

Follow this and additional works at: https://ro.uow.edu.au/buspapers

Part of the Business Commons

Research Online is the open access institutional repository for the University of Wollongong. For further information contact the UOW Library: research-pubs@uow.edu.au 


\title{
Assessment guiding learning: developing graduate qualities in an experiential learning programme
}

\author{
Abstract \\ As industry demands increase for a new type of graduate, there is more pressure than ever before for \\ higher education (HE) to respond by cultivating and developing students who are prepared for these \\ workplace challenges. This paper explores an innovative experiential learning programme built on the \\ principles of work-related learning that develops students to attain graduate qualities for competitiveness \\ in the business sector. The role and importance of assessment as a core influence for learning is \\ recognised and embedded into the programme, as well as the prevalence of meeting the needs of its \\ stakeholders. Issues concerning assessing work-oriented learning are explored as well as what \\ assessment methods might be most appropriate for enhancing and evaluating learning in this context. \\ Feedback from stakeholders on the structure of the programme and its assessment are discussed as well \\ as the question of how to maintain work-related programmes in HE. If such programmes continue to \\ focus assessment and design around student learning, students will not only have the opportunity to \\ apply their knowledge in a practical context, they will also be maximising their personal learning \\ outcomes with the added advantage of being better equipped to compete in an increasingly competitive \\ marketplace.

\section{Keywords} \\ era2015 \\ Disciplines \\ Business

\section{Publication Details} \\ Clements, M. David. \& Cord, B. Amelia. (2013). Assessment guiding learning: developing graduate \\ qualities in an experiential learning programme. Assessment and Evaluation in Higher Education, 38 (1), \\ 114-124.
}




\section{Assessment guiding learning: Developing graduate qualities in an experiential learning programme.}

\section{Professor Michael Clements}

Industry Engaged Learning, Swinburne University of Technology, Melbourne, Australia

\section{Bonnie Cord}

School of Management and Marketing, Faculty of Commerce, University of

Wollongong, Wollongong, Australia

Professor Mike Clements

University Professor of Industry Engaged Learning, H20, BA Building, Level 9,

Swinburne University of Technology, John St., Victoria, Australia, 3122. Telephone:

+61392145265 mclements@ swin.edu.au

Ms. Bonnie Cord

PhD Candidate, Building 40, School of Management and Marketing, Faculty of

Commerce, University of Wollongong, Wollongong, Australia, 2500. Telephone: +612 42215286 bcord@uow.edu.au 
Higher education (HE) continues to be challenged by both the private, public and community sector to provide graduates who, as employees, will enable them to effectively compete in an ever demanding environment. As the application of technology and communication media in business increases (Castells, 2000), organisations continue to seek graduates who can contribute to this competitive business sector (Nicholas, 2010).

In preparing students for the demands and expectations of industry, HE seeks to develop graduate qualities indicators in the education of students. Graduate qualities are largely determined by understanding the new global workplace and the challenges that students face as future employees. Leading international recruitment companies continue to seek students, who can differentiate themselves from their peers by being able to engage with the organisation, the community and the world (Nicholas, 2010). High performance work places also have high expectations of their employees, including the need to have interactive and creative capabilities. Employees are required to display skills and qualities such as leadership, team work, problem solving and initiative (Druskat \& Wheeler, 2003).

While many universities have developed a set of graduate qualities in an effort to build a profile for their graduates and provide a clear focus on delivery requirements of learning outcomes, classroom only learning may not provide enough context for students to develop these outcomes. A primary challenge for HE is designing learning outcomes and assessments that encourage development of graduate qualities in the work-placement context. This paper recognises the importance of an assessment mechanism for engaging learning and presents an innovative work-related model of 
assessment on an experiential learning programme to attain a desirable graduate profile. The paper begins with a review of existing work oriented approaches to learning and the current challenges in the design and assessment of such experiential learning programmes. A framework is presented, outlining assessment and evaluation practises in an intensive internship programme for cross-discipline business students that assist students in gaining specific graduate qualities through first-hand workplace experiences. This paper concludes by discussing feedback from key stakeholders in an attempt to determine the contribution of this programme to student learning, theory advancement, and in developing graduate profiles which will enable students to be more competitive in the workplace.

\section{Enabling students to attain a desirable Graduate Profile}

Equipping students to attain graduate outcomes requires a combination of knowledge development from a discipline perspective and from the opportunity to learn through application of such knowledge and experience (Crebert et al., 2004). Graduate qualities include the generic skills that undergraduates should obtain during the course of their study at University. Assessment within the Commerce Internship Programme (CIP) has been designed to encourage the development of the graduate qualities listed on page eight, which include generic skills such as team work, critical thinking, creative thinking and reflective practice. The assessments in the CIP have been designed to focus the students' attention on how they view the development of these skills over the course of the internship through their own self-reflection process. The assessment including a reflective journal enables students to examine their learning in relation to the development and attainment of graduate qualities that result from their exposure to 
the work environment where they can develop and test these qualities. As well as discipline competency standards, personal development of generic or transferable skills such as self appraisal, willingness to take responsibility, and ability to work as a team member are also desirable attributes for both potential employees and employers (Cord \& Clements, 2010). These desirable employee attributes create an opportunity in student skill development which experiential learning programmes in the workplace have addressed to different levels of success.

In the last decade experiential learning programmes (ELPs) have gained momentum in both the vocational education and training (VET) sector and HE. The authors have adopted a work related learning (WRL) mechanism (Moreland, 2005) that is synonymous with the development of the individual and that can translate into the attainment of graduate qualities. WRL is intended to enhance the student's ability to engage in working life and employability, including learning through the experience of work and is often considered as utilising higher order metacognitive skills, such as judgment (Hager, 2000) and reflection (Brockbank et al., 2002).

The experiential learning framework presented in this paper has been designed to capture and enhance the personal growth and learning opportunities for the student in a supported environment. According to Boud (2001, p. 46) work-related programmes need to be "flexible and responsive to the circumstances of the learner and of the work setting" and must not focus on a narrow competency based approach, rather be more open to the learning derived from the student experience. The design of the assessments, therefore, becomes very important in enabling students to maximise, and be able to display, both formal and informal learning integrating ways in which they can 
demonstrate their graduate qualities. Assessment needs to be appropriate in design so that it encourages the student to learn relevant subject knowledge, engage with their work context, develop graduate qualities, and demonstrate the learning from the experience itself.

\section{The importance of assessment for work related learning}

The importance and role of assessment is crucial "rather than being an add-on or a test of pre-ordained information, it is central to the process of learning itself" (O'Toole, 2007, p.52). There are several reasons why students are assessed. Assessments can help identify and evaluate strengths and weaknesses, grade student learning, monitor and provide feedback on student progress, assess competence and help predict future behaviour. For teachers, assessments can provide feedback on the effectiveness of their methods and styles and help plan how to better manage student progress (Allin \& Turnock, 2007), while for the student they play a crucial role in support and motivation (Broadfoot \& Black, 2004).

The challenge with experiential learning assessments is attributed to the extent in which placement experiences amongst students differ (Fell \& Kuit, 2003), therefore assessments must be designed to support and encourage the learning process and individual development in their different experiences. Learning is also a continuous process that is grounded in experience, with one experience implicating how we deal with the next (Kolb, 1984; Dewey, 1933). Normal practice in HE in the UK appears to suggest that all courses contain learning outcomes so that the student and other 
stakeholders can see the tangible benefits for course participation. In experiential learning programmes, however, the focus is on individual learning which will differ amongst students depending on a number of environmental, organisational and personal factors such as organisational culture, tasks performed and personality. In accordance with subject requirements, ELPs that are for academic credit, must formulate assessments in line with anticipated learning outcomes, however equal focus must be on the individual process of learning to enhance preparation of students to meet the demands of the workplace.

There are several appropriate assessment methods for work-related learning through which students may be assessed such as memorandum reports, portfolios, dissertations, theses, presentations and poster displays (Gray, 2001). Many ELPs have indicated that they use some form of journal or diary and reflective learning techniques in their assessment. Dewey (1933) promoted reflection as a means by which teachers can act with foresight and plan for the future based on their learning from past classroom experiences. Schön (1983) furthered the notion by describing two main forms of reflection, reflection in-action and reflection on-action. While Schon's conception of reflection in-action is in the occurrence of unexpected events, reflection in-action has also been closely linked to the phenomenon of mindfulness (Jordan, Messner \& Becker, 2009), which is an increased awareness of specific circumstances in a given situation. Reflection on-action is more closely linked to the cyclical nature of experiential learning (Moon, 1999) as material must be drawn on to learn through the process of reflection by making connections and drawing on knowledge.

\section{Structure of internship model for experiential learning}


This programme supports students' transition from higher education into the workforce through developing workplace opportunities for students to develop graduate qualities through experiential learning. The graduate qualities adopted by the Faculty of Commerce at the University of Wollongong are to be informed, innovative and flexible, socially responsible, connected and effective communicators. The programme was specifically designed to provide students the opportunity to develop these graduate qualities by combining their new university knowledge (theory) with the daily interaction of people in a workplace context in this new professional environment. This is often a new experience for the students which enables them to develop the softer skills highly regarded by employers which include the graduate qualities.

The programme is short, flexible and competitive. The work placement component of the programme consists of 16 days in an organisation completed during one session to complement and enhance existing study by applying theory in practice. Entry into the programme is competitive, with each year seeing approximately 80-100 students placed through the programme. Host organisations are carefully selected by the facilitators of the programme and are often recruited through referral from other host organisations that have previously been part of the programme. The criteria used for the selection of the host organisation, includes the organisations ability to provide a worthwhile learning experience for the student in their discipline. This is determined in an interview with the host organisation on a case by case basis. The host organisations are provided with guidelines on the type of experience expected for the students. They are also advised on any conditions of placement, and guided through the placement process with the 
university coordinator, ensuring the tasks to be undertaken during the placement are agreed and understood by all parties.

Students apply online through the University site, based on an organisation identifying a need for particular student skills. The organisation then, after interviews, makes the final student selection to best suit the opportunity they are offering. Successful students are then enrolled in the CIP (COMM390), which is a third year elective subject.

The success of the programme can be attributed to its stakeholder model, that is the degree to which it aims to meet the needs of the students, faculty and host organisations. Unlike many ELPs, CIP is not governed by accreditation criteria, government guidelines or professional associations and therefore can focus on meeting the needs of its stakeholders. While the assessments of CIP guide student learning and engagement, the structure and foundation of the programme has the key interest of developing graduate qualities for the students that participate in the programme. The structure of the programme provides a unique off-campus, professional opportunity for students to explore, challenge, and innovate in how they connect their understanding to practice. It is this process that helps students develop their graduate qualities such as being innovative and flexible, informed and connected in the workplace. The day to day challenges of the business encourage the students to be better communicators and to understand both the social and ethical dimensions of business. Students are supported in their transition into the workplace through regular contact, workplace visits, phone calls and an initial pre-placement meeting. This meeting is attended by the coordinator, student and industry mentor and aims to orient the student prior to the scheduled 16 days. At this time expectations, roles and other logistical issues are discussed, and both the host organisation and student sign agreements regarding code of conduct and the 
university's legal obligations, such as Intellectual Property (IP), insurance, Occupational Health \& Safety $(\mathrm{OH} \& \mathrm{~S})$, and confidentiality. On commencement of the first day of placement an induction process including $\mathrm{OH} \& \mathrm{~S}$ is completed with the student by the host organisation. 


\section{CIP assessment and graduate qualities}

The learning strategy is detailed in the subject description which is to 'provide an opportunity for students to integrate and apply their knowledge learnt at university in an industry context'. The subject comprises of the following learning outcomes:

1. Identify organisational practices and procedures, including work related issues.

2. Apply knowledge learnt at university to critically analyse organisational practices and procedures.

3. Demonstrate effective communication skills, orally and written, within a professional environment.

4. Demonstrate an appreciation for discipline in the context of the work place.

5. Participate as a team member in a work environment, for the purpose of resolving work related issues.

6. Demonstrate analytical and problem solving skills, in proposing solutions to real business problems.

The graduate qualities include being:

Informed: have developed skills for independent thinking and life-long learning Innovative and Flexible: be innovative in their thinking and work practices, be flexible in their approach and be able to apply creativity and logical analysis to solving business and social issues.

Socially Responsible: appreciate the social and ethical dimensions of business. 
Connected: be able to work and network effectively with others and connect ideas and practice.

Communicators: demonstrate an effective level of interpersonal, written and verbal communication skills.

The graduate qualities listed are provided for the students in the subject outline. These are not specifically taught as part of the subject, but rather students are encouraged to individually develop and integrate these skills when participating in the subject.

The CIP subject utilises both face-to-face and online learning to prepare and assess students to align with the learning outcomes and graduate qualities. The combination of a traditional and innovative approach in subject design provides students with a blended learning environment that is flexible, supported and meets their needs. The subject includes two lectures and three assessment components: E-logs, modules and a reflective journal. A lecture is presented at the beginning of the placement for preparation and expectations management while the last lecture conducted postplacement debriefs the students to share learning amongst peers. Assessment tasks have set due dates except for E-Logs which are based on the placement days, negotiated between the organisation and student. The assessments are graded as satisfied or unsatisfied, similar to the grading seen in performance subjects in Creative Arts and other experiential learning programmes (e.g., Beard, 2007). This grading system, which uses no specific numerical marks, supports learning behaviour away from the classroom. Also allowing students the flexibility to fully participate in their own learning rather than focus on marks, as a representation of what they have learnt (Boud \& Falchikov, 2006). 
All assessments are submitted online through an e-learning forum for the subject. Through electronic submission, students are given the flexibility to work on their assessments away from the campus, complementing their off-campus practical placement experience. An e-discussion forum allows students to engage with each other and the academic advisors, a mechanism to generate deeper reflection. Informal feedback from all three stakeholders (student, industry and academic tutors) is a valuable source of information, and is regularly collected through ongoing verbal and written communication. This feedback forms part of the regular review into the programme, academic teaching practices and assessment. Based on feedback from industry partners which was received prior to the establishment of the programme, they identified time and resourcing as concerns when taking on interns. Therefore all assessments are conducted and graded by academic facilitators of the programme. This also overcomes issues with multiple and untrained markers (Brodie \& Irving 2007; Fell $\&$ Kuit, 2003) as the academic advisors are educated in learning enquiry approaches and reflection principles to aid student development, along with assisting students make changes that will enhance their learning practice and contribution to the organisation (Boud \& Costley, 2007). The following section explores the assessment and preparation mechanisms to enhance student learning opportunities for developing graduate qualities through their experience in the workplace.

Two interactive lectures are delivered during the semester, one prior to the student placement and one after completion of their placement. Lectures offer support, guidance, information and a chance to interact and share feelings and stories with other students who have been on placement. The first lecture discusses expectations of the student and host organisations, and provides students with case studies and advice on 
how to manage their own experiences to get the most out of the learning opportunity. Students are encouraged to interact and learn about reflection and learning principles. Graduate qualities listed in the outline are discussed and students are encouraged to seek out ways to develop these skills whilst in their work placement. The structure provides a safe learning space for the student enabling them to put themselves in a test environment where they can experience in practice what they have been learning in theory, at the same time ensuring they are informed, innovative and flexible in their approach and ensuring that they are communicating their thoughts to their supervisor in relation to the task required. This application enables the student to develop their graduate qualities. The students' ability in demonstrating these valuable qualities is attained through feedback from the host organisations by telephone conversation as part of the post placement follow up. To this extent the measure of the student attaining these skills is both acknowledged by the student in their own self-development through their reflective journal and the host organisation in their feedback to the University. A compulsory non-assessable requirement is for students to complete an on-line workshop before entering the workplace, which teaches and quizzes students on equity issues, concepts and application which have been explained to them in the first lecture. The second lecture is at the conclusion of the placement and semester, and aims to debrief, reflect, share and gather feedback from the students. Through discussion, students identify, contrast or extend each other's learning experiences. This lecture provides guidance for how students can take their learning experience and apply it in their future endeavours.

\section{Teaching and learning approach and assessment practices}


This section details the approach taken utilising a series of assessments to encourage the student to reflect upon their own development of the graduate qualities through their participation in the internship programme. The assessment helps the student to challenge themselves through reflection to better understand how and to what extent they have developed the graduate qualities at a personal level. Recording reflections on experiences is crucial to the development of the student and their learning and is the purpose of this progressive assessment. The accumulation of constant reflective thoughts forms a major part of the personal learning journey.

\section{Method: E-logs}

An E-log or electronic diary is completed for each day the student is on placement. The purpose of the E-log is for the student to document their activities and thoughts progressively throughout their experience to enable reflection and subsequent learning. The E-log also assists the students in their final reflective journal assessment and allows advisors to monitor and provide feedback on their development. Due to the timeliness of the E-logs, advisors in the form of tutors can guide learning and, if necessary, intervene if issues arise with their reflections or placement (Boud \& Costley 2007). In an effort for differentiation, the E-logs are written whilst participating in the placement, allowing changes to be made and experiences to be modified, as the student is still living in the experience. The reflective journal is written post-placement, giving time to reflect on the discoveries made in the E-logs and the action that has taken place, allowing for deeper reflection and learning, this should include self-reflection in regard to the attainment of graduate qualities. The next assessment discussed aims to direct the students focus to an awareness of their workplace environment, their role, skills and 
contributions, once again includes a focus on the student developing their graduate qualities.

\section{Method: Learning Modules}

As CIP includes a range of disciplines, modules are focused on generic workplace learning skills. Modules are enhanced by a relevant case study and reading available through the E-Learning forum. The assessment requires the students to consider their expectations, anticipations and the relevant readings and respond to set questions on each module area. The modules include; the workplace environment, team work, critical and creative thinking. The assessment encourages students to think about these issues with the purpose of preparing students for their transition into the workforce at the completion of their studies. Students are required to complete all the learning for the modules during the placement.

\section{Assessment of connectedness and future direction}

Overall, reflection may assist the student in making the connections to the learning implications for their future, including career choices and further study. Conducted after placements, this assessment uses reflection to help guide the student in how they might adjust their application to assist future learning.

\section{Method: Reflective Journal}

The final piece of assessment considers critical reflection around structured themes. As with the modules, the reflective journal provides an E-reading and a case study, used as examples of other placements and to assist the student in how they might respond in their own reflective journal. Students are required to draw on the readings, their E-logs 
and modules, as well as their previous experience and knowledge to reflect on their placement and answer a series of questions, evidence of connection making evoking reflection on-action learning (Moon, 1999). The reflective journal requires the student to reflect on their own learning which took place in relation to the practise. During this reflective assessment students are required to reflect on how they had developed and attained exposure to graduate qualities as an outcome of their internship placement. This assessment task requires the student to provide an overview of the organisation and their key roles, outline the skills applied on internship that were developed at university, identify the skills developed during placement including the development of graduate qualities and personal strengths, reflecting on their learning style and their overall experience. The modules are covered twice, the first time soon into their placement concentrating on their expectations of workplace elements and the second time looking at how these were actually addressed in the workplace and integrated into their reflective journal.

\section{Challenges for maintaining experiential programme contribution to graduate qualities}

Higher education programmes have tended to focus on the acquisition of knowledge rather than practice of knowledge (Boud, 2001) which has been a core deliverable for vocational oriented programmes. As HE strives to better prepare and indeed provide an environment for the development of graduate qualities, the structure and assessment of such programmes becomes critical in influencing learning outcomes for its participants. 
Traditional assessment for internship programmes have been project outcomes with a tendency to focus on the application of knowledge to a business problem. It often emphasises problem solutions rather than formulation of a problem in a context driven environment which can render the activity unrealistic (Boud \& Falchikov, 2006). The CIP assessment is designed for students to reflect on their learning experience, which might involve solving a problem, but more importantly, assist the students to understand what they learnt from solving the problem.

The flexibility of CIP has been very well received amongst students, as it complements their current lifestyle. As one student remarked, 'being able to work off campus and submit assessments via the e-learning site freed up valuable time that could be spent completing work from other subjects or pursuing other activities'. Students describe the internship experience as an 'empowering journey' and acknowledge satisfaction in making real contributions that benefit the company. Approximately 80-100 students per year participate in this programme, across disciplinary backgrounds with the majority (over $80 \%$ ) reporting back that they discover a lot about themselves and their abilities by undertaking the programme.

Responses on the CIP assessment design largely supports the current structure, however a few recommendations were identified by students. Feedback on the E-log was that it was an excellent recording mechanism as well as forum to enhance learning through reflection. As one student stated, 'It's a different way of learning and it opens the mind up to how we learn, which can help us learn in the future'. Students see the value in formal reflection however it was acknowledged that for some, it became time consuming and the students suggested debriefing with a peer in addition to the formal 
reflection requirements. Student feedback on the modules was not particularly directed towards the e-readings. One student commented that they were 'too academic'; while many stated that they related best to the applied case studies. 'The subjects at first seemed strange, for example creative thinking, but in the end I was surprised what I had learnt'. The reflective journal was the assessment most enjoyable for students, as it provided the framework to reveal their individual learning journeys (Fell \& Kuit, 2003). Through the reflective journal, growth, development and changes were recognised, enhancing the students self belief and ability. The importance of learning through assessments (O'Toole, 2007) is duly noted by students, 'I don't think I would have considered my internship so valuable without the reflection modules/log because they made me think about my experiences'. Students agreed that they would integrate reflection into their personal and professional lives, however less than half considered continuing reflection through some form of diarising.

Earlier this paper identified the dilemma for industry and HE regarding the issue of how the transferability of learning from both the classroom and work oriented programmes actually translates to the student attainment of graduate qualities. Development of interactive and creative capabilities, skills and qualities such as leadership, team work, problem solving and initiative (Druskat \& Wheeler, 2003), adaptability and flexibility are only possible by being exposed to real challenges in a real work context.

Challenges remain prominent in the pursuit of designing accessible quality driven work oriented learning programmes which enable students to graduate with the qualities desired by employers. The CIP discussed provides one such programme to develop graduates who are not only prepared for industry, but who potentially can add value to 
an organisation. In saying this, challenges exist in the university's ability to integrate WRL programmes into curriculum.

A core dilemma for HE revolves around the appropriate development of assessment criteria that meets academic standards but which also does not limit or constrain learning for the student. Boud \& Falchikov (2006) state that "Higher education has an important role in the preparation of students for what is to follow because it is becoming the final systematic stage of education for the majority of the population, and the key stage for all those proceeding to professional work, indeed, relatively few of the activities of work and life can be characterised by the degree of systematisation and formality found within education institutions" (Boud \& Falchikov, 2006, p 404). To this end our programme seeks to align with these insights in that it encourages the student to reflect and self evaluate their own learning in the workplace which prepares the student for learning beyond the workplace.

Whilst student and industry feedback suggests positive outcomes for personal development following the Faculty of Commerce graduate qualities such as being informed, innovative and flexible, socially responsible, connected and effective communicators, more research is underway as to how we can encourage further engagement from students in their own learning. Much of this discussion revolves around student self assessment. Boud and Falchikov (2006), suggest that while evidence suggests a move towards engaging students in assessment, there is sufficient concern that current practises on lecturer designed assessment only encourages students to comply with standards rather than take ownership of the problem in the workplace and indeed resolve to solve themselves. It is our intention to further pursue this concept of 
student driven self assessment in conjunction with lecturer assessment so that over time, students will be able to design their own plan and assess their own learning needs to solve the problems presented to them in the workplace as a matter of routine. Then they will be drivers on the journey for life-long learning. 
References

Allin, L. \& Turnock, C. (2007). 'Assessing Student Performance in Work-Based Learning', Assessment for Work-based Supervisors. Retrieved 18 January, 2010, from http://www.practicebasedlearning.org/

Beard, D. F. (2007). 'Assessment of Internship Experiences and Accounting Core Competencies', Accounting Education 16(2): 207-220

Boud, D (2001). 'Creating a work-based curriculum'. In Boud, D and Solomon, N (eds) Work-Based Learning: A new higher education, Buckingham, SRHE and The Open Univeristy Press

Boud, D. \& Costley, C. (2007). 'From project supervision to advising: new conceptions of the practice', Innovations in Education and Teaching International 44(2): 119 $-130$

Boud, D. \& Falchikov, N. (2006). 'Aligning Assessment with Long Term Learning', Assessment and Evaluation in Higher Education 31(4): 399-413

Broadfoot, P. \& Black, P. (2004). 'Redefining assessment? The first ten years of assessment in education', Assessment in Education 11(1): 7-27

Brockbank, A., McGill, I \& Beech, N. (2002). Reflective Learning in Practice. Aldershot, Gower

Brodie, P. \& Irving, K. (2007). 'Assessment in work-based learning: investigating a pedagogical approach to enhance student learning', Assessment and Evaluation in Higher Education 32: 11-19 
Castells, M. (2000). 'Information Technology and Global Capitalism', On the Edge: Living with Global Capitalism. In W. Hutton and A. Giddens. London, Jonathan Cape: pp.52-74

Cord, B. A., \& Clements, M. D. (2010). 'Pathway for Student Self-Development: A learning orientated internship approach', Australian Journal of Adult Learning 50(2): $287-307$

Crebert, G., Bates, M., Bell, B., Patrick, C.J., \& Cragnolini, V. (2004). Developing generic skills at university, during work placement and in employment: graduates' perceptions. Higher Education Research \& Development, 23(2), 147165

Dewey, J. (1933). How We Think. Boston, D C Heath \& Co.

Druskat, V. U. \& Wheeler, J. V. (2003). 'Managing from the boundary: the effective leadership of self-managing work teams' Academy of Management Journal 46(4): 435-457

Fell, A. \& Kuit, J. A. (2003). 'Placement Learning and the Code of Practice: Rhetoric or Reality?' Active Learning in Higher Education 4(3): 214-225

Gray, D. (2001). 'A briefing on work-based learning', York, Higher Education Academy.

Hager, P. (2000). 'Knowledge That Works: Judgement and the University Curriculum'. In Symes, C. and McIntyre, J. (eds.) Working Knowledge: The New Vocationalism and High Education.Maidenhead: SRHE and Open University Press: $47-65$ 
Jordan, S, Messner, M \& Becker, A. (2009). 'Reflection and Mindfulness in Organizations: Rationales and Possibilities for integration', Management Learning 40(4): 465-473

Kolb, D.A. (1984). Experiential Learning: Experience as the source of learning and development, New Jersey, Prentice Hall.

Moon, J.A. (1999). Reflection in Learning and Professional Development: Theory and Practice, London, Kogan Page.

Moreland, N. (2005). Learning and Employability (Series 2), Work related learning in higher education, Higher Education Academy.

Nicholas, P. (2010). 'Switch in time for success' The Weekend Australian on 23 January

O'Toole, K. (2007). 'Assessment in Experiential Learning: The case of a public policy internship', Education Research and Perspectives 34(2): 51-62

Schön, D. A. (1983). The Reflective Practitioner. San Francisco, Joey-Bass. 